\title{
Erratum to: A nonlinear Hvorslev surface for highly overconsolidated soils: elastoplastic and hypoplastic implementations
}

\author{
X. S. Shi ${ }^{1} \cdot$ I. Herle $^{1} \cdot$ K. Bergholz ${ }^{2}$
}

Published online: 23 August 2017

(C) Springer-Verlag GmbH Germany 2017

\section{Erratum to: Acta Geotechnica DOI 10.1007/s11440-016-0485-1}

The original article was published with the following errors:

In Eq. (19), the semicolon has been included by mistake. The correct equation is given below:

$\mathrm{d} p_{\mathrm{c}}^{\prime}=\frac{p_{c}^{\prime}}{\lambda^{*}-\kappa^{*}} \mathrm{~d} \varepsilon_{\mathrm{v}}^{\mathrm{p}}=\frac{p_{c}^{\prime}}{\lambda^{*}-\kappa^{*}} \frac{\partial g}{\partial p^{\prime}} \mathrm{d} \zeta$

In Eqs. (32) and (33), parentheses were missed. The correct equations are given below:

$\bar{f}_{\mathrm{d}}^{\mathrm{A}}=\xi\left(\frac{M^{2}-\eta^{2}(1-k)}{M^{2}}\right)^{k /(2-2 k)}$
$\bar{f}_{\mathrm{d}}^{\mathrm{A}}=\left(\frac{M}{\eta}\right)^{1 /\left(1-\beta-\kappa^{*}(1-\beta) / \lambda^{*}\right)}$

Finally, the notations 'OC-50 $\mathrm{kPa}^{-1}$, 'OC-50 $\mathrm{kPa}^{-2}$, 'OC-50 $\mathrm{kPa}^{-3}$, 'OC-50 $\mathrm{kPa}^{-4}$, are incorrect in the entire article. The correct notations are given below:

\section{'OC-50kPa-1', 'OC-50kPa-2', 'OC-50kPa-3', 'OC- $50 \mathrm{kPa}-4$ '}

The original article has been updated accordingly. doi:10.1007/s11440-016-0485-1.

X. S. Shi

Xiusong.Shi@mailbox.tu-dresden.de

I. Herle

Ivo.Herle@tu-dresden.de

K. Bergholz

katharina.bergholz@baw.de

1 Institute of Geotechnical Engineering, Technische Universität Dresden, 01062 Dresden, Germany

2 Federal Waterways Engineering and Research Institute, Karlsruhe, Germany 